\title{
Bilateral Submandibular Gland Aplasia: An Unusual Cause of Sublingual Swelling-The Role of Imaging in Patient Management
}

\author{
Srividya B Thimmappa ${ }^{1} \quad$ Abhishek Suman $^{1}$ Rashmi Dixit $^{1} \quad$ Anju Garg $^{1}$ \\ ${ }^{1}$ Department of Radiodiagnosis, Maulana Azad Medical College, New \\ Delhi, India \\ Address for correspondence Rashmi Dixit, MDRD, L23 Nivedita Kunj, \\ Sec 10, RK Puram, New Delhi, 110022, India \\ Indian J Radiol Imaging 2021;31:1043-1046. \\ (e-mail: drrashmidixit@gmail.com).
}

\begin{abstract}
There are very limited reports of aplasia of bilateral submandibular glands. We report the case of a 55-year-old male who presented with nontender palpable sublingual masses. On computed tomography and magnetic resonance imaging, bilateral submandibular gland aplasia and compensatory hypertrophy of bilateral parotid and sublingual glands were seen with herniation of hypertrophied sublingual glands

Keywords

- submandibular gland aplasia

- sublingual swelling

- mylohyoid through the bilateral mylohyoid muscles presenting as palpable sublingual region masses. Additional finding of bilateral accessory parotid glands was also noted. Prolapsed hypertrophied sublingual glands should be considered in patients presenting with bilateral sublingual masses to avoid unnecessary invasive procedures. We suggest radiological evaluation of such cases prior to any intervention.
\end{abstract}

\section{Introduction}

The first case of bilateral submandibular gland aplasia was presented in 1885 by Gruber. ${ }^{1}$ The submandibular salivary gland development is a finely regulated process, involving well-timed sequences of cellular and tissue events. For this reason, different types of structural congenital anomalies, ranging from asymptomatic anatomical variants to alterations, are associated with syndromic conditions. ${ }^{2}$ Off these major salivary gland aplasia is usually seen in association with congenital disorders such as lacrimo-auriculo-dento-digital syndrome, mandibulofacial dysostosis, Treacher Collins syndrome, hemifacial microsomia, and ectodermal dysplasia associated with aplasia or dysplasia of lacrimal or thyroid glands. ${ }^{2}$ However, isolated aplasia of major salivary glands is very rare entity; when present, it most commonly affects the parotid gland. Clinically, patients may be asymptomatic or may present with dryness of the mouth, have difficulty in chewing and swallowing, and suffer from dental caries due to hypo function of salivary glands. Associated pseudomasses can be seen as a result of compensatory hypertrophy of the other major and minor salivary glands along with presence of accessory salivary glands. ${ }^{3}$

\section{Case Report}

A 55-year-old male presented with swelling in the floor of mouth for the last 6 months and had mild difficulty in chewing food and swallowing. He had no history of prior head and neck cancer or surgery. Bilateral nontender sublingual region masses were noticed with bulge along both sides of midline in the floor of mouth and submandibular gland salivary duct (Wharton duct) was not visualized on oral examination. No dental caries were seen. No constitutional symptoms, local inflammatory signs, or regional adenopathy were observed. Clinically and on ultrasonography from outside clinic, a provisional diagnosis of ranula was published online

December 13, 2021
DOI https://doi.org/ 10.1055/s-0041-1740260. ISSN 0971-3026.

\footnotetext{
(C) 2021. Indian Radiological Association. All rights reserved. This is an open access article published by Thieme under the terms of the Creative Commons Attribution-NonDerivative-NonCommercial-License, permitting copying and reproduction so long as the original work is given appropriate credit. Contents may not be used for commercial purposes, or adapted, remixed, transformed or built upon. (https://creativecommons.org/ licenses/by-nc-nd/4.0/)

Thieme Medical and Scientific Publishers Pvt. Ltd., A-12, 2nd Floor, Sector 2, Noida-201301 UP, India
} 

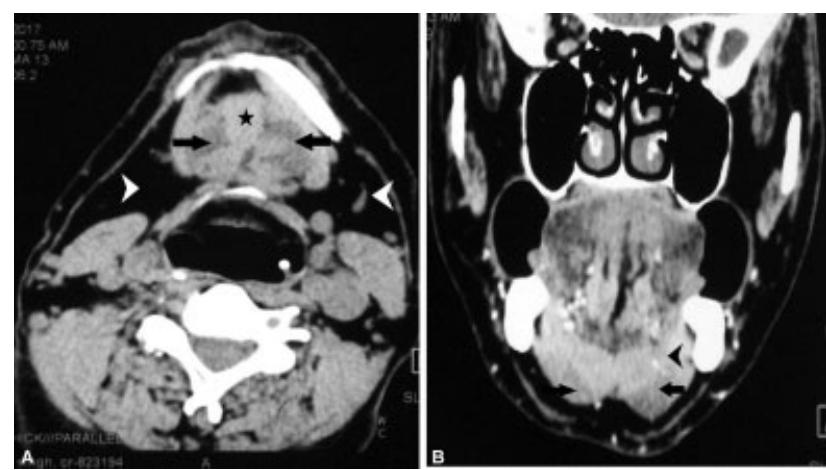

Fig. 1 Radiographic CT image of parotid, sublingual and submandibular salivary glands.

considered with possibility of neoplastic conditions as the differentials. He was referred for imaging prior to planned needle aspiration cytology.

Computed tomography (CT) of the soft tissues of the neck with intravenous contrast revealed absence of bilateral submandibular glands with normally enhancing bilateral hypertrophied sublingual salivary glands that showed inferior lobulated projections splitting the mylohyoid muscle protruding into the submandibular spaces (left >right) ( - Fig. 1A and B). No calculus, stranding, or ductal dilatation was noted. Similar findings were confirmed on a noncontrast magnetic resonance (MR) study (T1-weighted, T2-weighted, and fat-suppressed T2-weighted images in axial and coronal planes) (-Fig. 2A-C). Additional finding of bilateral symmetrical enlargement of parotid glands and accessory parotid glands was also observed on CT and MRI. The hypertrophied parotid and accessory parotid glands were homogenous with distinct margins and no area of differential echogenicity, attenuation, or intensity. No surrounding inflammatory changes were seen. Patient was further advised for the sialography-gold standard investigation; however, patient denied to undergo sialography. The final imaging diagnosis of bilateral submandibular gland aplasia with associated hypertrophied bilateral parotid and sublingual glands, accessory parotid glands, and splitting of mylohyoid sling by hypertrophied sublingual salivary glands was made. This obviated the need for any intervention and patient was sent home after appropriate counselling.

\section{Discussion}

Agenesis or aplasia of the major salivary glands is very rare entity and it most commonly involves the parotid gland among the other major and minor salivary glands. When present, it is usually associated with multiple other developmental head and neck anomalies. ${ }^{2}$ Absence of submandibular gland may be associated with hypertrophy of the rest of major or minor salivary glands. In previous case reports ${ }^{4}$ of bilateral submandibular gland aplasia or agenesis, bilateral sublingual hypertrophy accompanied this congenital absence, which was also seen in our patient.

Pathogenesis of bilateral salivary gland aplasia is unknown; however, it is most likely owing to a disturbance during the fetal development. Major salivary glands development is from the proliferation of oral ectoderm and outpouching at 4 to 8 weeks of in utero development. Parotid gland develops first followed by submandibular gland and other major and minor salivary glands. ${ }^{2}$

The mylohyoid muscle is classically thought of and depicted as a continuous muscular barrier between the sublingual and submandibular spaces. The muscle, in fact, is often discontinuous. Anatomic and surgical literature have demonstrated that the defects may contain sublingual or submandibular salivary tissue, fat, blood vessels, or all three components. ${ }^{5-7}$ It inserts on the slightly obliquely oriented mylohyoid line on the medial surface of the mandible, with the posterior aspect more cranial than the anterior aspect. The muscle is thickest posteriorly, and thins as it approaches the mental tubercle. ${ }^{7}$

Submandibular gland aplasia may be associated with caries of mandibular permanent incisor teeth, as well as other signs of salivary hypofunction, such as dry mouth, disturbed oral sensation, and oral infections. ${ }^{4}$ In a case reported by Mathison and Hudgins, ${ }^{8}$ bilateral submandibular gland aplasia in a 34-year-old female patient with accompanying nodular-sclerosing Hodgkin's lymphoma, the patient did not show any sign of salivary hypofunction. Another
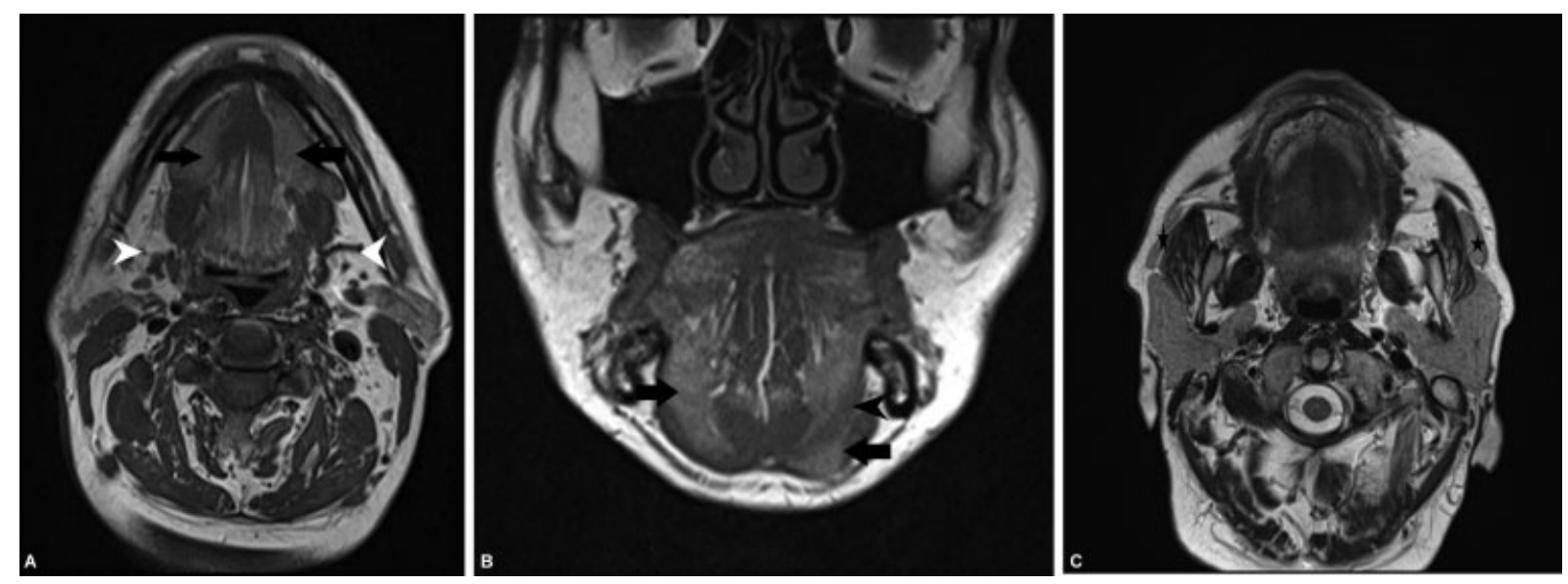

Fig. 2 (A and B) Schematic diagram of mylohyoid muscle and genioglossus muscle, sublingual and submandibular spaces. 
study by Ahmed et al also did not show such clinical symptoms in their 62-year-old male patient. Similarly, our patient did not suffer any major problem related to salivary deficiency. As in the previous stated cases, we believe this absence of oral symptoms is attributable to compensatory bilateral sublingual gland hypertrophy.

White et $\mathrm{al}^{3}$ reported the deficiencies in mylohyoid muscle in $77 \%$ of patients who presented with submandibular gland aplasia. These defects may contain variable amounts of fat, blood vessels, and salivary tissue. Accessory salivary tissue was identified in $37 \%$ of individuals who underwent scanning. They found the hypertrophied sublingual glands located in the mylohyoid defects are seen herniating into bilateral submandibular spaces to present as palpable masses. However, this extremely rare entity has been reported only once in literature by Ahmed et al. ${ }^{9}$ They reported a case of nonsyndromic bilateral submandibular gland aplasia with hypertrophied sublingual salivary tissue, the latter herniating through the mylohyoid defect to present as a palpable mass on the left side with corresponding CT findings in a pediatric patient who had bilateral palpable and visible masses with modified Valsalva maneuver.

Incidental absence of the right submandibular gland in a 35-year-old woman, with a "mass" in the right sublingual space, has been reported in previous literature. ${ }^{10,11}$ There were no associated calculi or other lesions, and the location of mass was above mylohyoid muscle sling. Their hypertrophy of the sublingual gland was seen in this instance.

There are various imaging techniques that help in diagnosing salivary gland aplasia, which include CT, MRI, ultrasonography, sialography, or nuclear medicine (99Tcm-pertechnetate) studies. ${ }^{10,12,13}$ Among various imaging techniques, sonography is cheap, noninvasive and widely available, and useful imaging technique. As in our case, many radiologists may prefer MR and CT imaging for better anatomical delineation and characterization of the abnormality. However, an elaborate sonographic examination by an experienced radiologist may be adequate. Inflammation-in particular, viral sialadenitis, tumors and dermoid cysts-should be included in the differential diagnosis of sublingual gland enlargement. Of these, bilateral enlargement is most likely to be seen in viral sialadenitis. Submandibular gland lesions include various benign and malignant lesions, in which benign lesions include pleomorphic adenoma, while malignant lesions include adenoid cystic carcinoma, mucoepidermoid carcinoma, metastasis, and lymphoma. ${ }^{14}$

Sialosis ${ }^{15}$ is a chronic, bilateral, diffuse, noninflammatory, nonneoplastic swelling of the major salivary glands that primarily affects the parotid glands, but occasionally involves the submandibular glands and rarely the minor salivary glands seen in patients with diabetes, malnutrition, and alcoholism. In such cases, clinical and imaging findings would be helpful in arriving at the correct diagnosis, where submandibular salivary glands would be seen in its normal location, and are associated with gland heterogeneity.

\section{Conclusion}

Symmetrical submandibular gland aplasia associated with bilateral sublingual gland hypertrophy should be kept in mind in patients with bilateral submandibular masses to avoid unnecessary biopsy or surgical interventions. CT or MRI should be performed before any intervention. ${ }^{10,12}$ This prevented the need for any intervention and the patient was sent home after appropriate counseling.

\section{Authors' Contribution}

Srividya B Thimmappa was involved in conceptualization, designing, definition of intellectual content, literature search, data acquisition, data analysis, and manuscript preparation. Abhishek Suman was involved in conceptualization, designing, definition of intellectual content, literature search, data acquisition, data analysis, manuscript preparation, manuscript editing, and review. Rashmi Dixit was involved in conceptualization, designing, definition of intellectual content, literature search, data analysis, manuscript editing, and review. Anju Garg edited and review the manuscript. Abhishek Suman, Rashmi Dixit, and Anju Garg have provided guarantee for this manuscript.

\section{Source(s) of Support}

Nil.

Conflicting Interest (If present, give more details)

Nil.

\section{Acknowledgment}

Thanks to Almighty for giving me strength and ability to complete this case report.

I am extremely thankful to Dr. Abhishek suman, Dr. Rashmi Dixit (professor), and Dr. Anju Garg (HOD of Dept of Radiodiagnosis) Maulana Azad Medical College, New Delhi, for their valuable support in completion of case report.

\section{References}

1 Yilmaz MD, Yücel A, Dereköy S, Altuntaş A Unilateral aplasia of the submandibular gland. Eur Arch Otorhinolaryngol 2002;259(10): 554-556

2 Togni L, Mascitti M, Santarelli A, et al. Unusual conditions impairing saliva secretion: developmental anomalies of salivary glands. Front Physiol 2019;10:855

3 White DK, Davidson HC, Harnsberger HR, Haller J, Kamya A. Accessory salivary tissue in the mylohyoid boutonnière: a clinical and radiologic pseudolesion of the oral cavity. AJNR Am J Neuroradiol 2001;22(02):406-412

4 Srinivasan A, Moyer JS, Mukherji SK. Unilateral submandibular gland aplasia associated with ipsilateral sublingual gland hypertrophy. AJNR Am J Neuroradiol 2006;27(10):2214-2216

5 Gaughran GR. Mylohyoid Boutonniere and sublingual bouton. J Anat 1963;97:565-568

6 Agarwal AK, Kanekar SG. Imaging of submandibular and sublingual salivary glands. Neuroimaging Clin N Am 2018;28(02):227-243

7 Vidić B, Melloni BJ. Applied anatomy of the oral cavity and related structures. Otolaryngol Clin North Am 1979;12(01):3-14 
8 Mathison CC, Hudgins PA. Bilateral submandibular gland aplasia with hypertrophy of sublingual glands. Otolaryngol Head Neck Surg 2008;138(01):119-120

9 Ahmed M, Strauss M, Kassaie A, Shotelersuk V, DeGuzman R. Bilateral submandibular gland aplasia with clinico-radiological mass due to prolapsing sublingual salivary tissue through mylohyoid boutonniere: a case report and review. Dentomaxillofac Radiol 2009;38(02):121-124

10 Haktanir A. CT and MR findings of bilateral submandibular gland aplasia associated with hypertrophied symmetrical sublingual glands herniated through mylohyoid defects. Dentomaxillofac Radiol 2012;41(01):79-83

11 Neagu D, Patiño-Seijas B, Luaces-Rey R, Collado-López J, GarcíaRozado-González Á, López-Cedrún-Cembranos JL. Aplasia of the lacrimal and major salivary glands (ALSG). First case report in Spanish population and review of the literature. J Clin Exp Dent 2018;10(12):e1238-e1241

12 Kara M, Güçlü O, Dereköy FS, Resorlu M, Adam G. Agenesis of submandibular glands: a report of two cases with review of literature. Case Rep Otolaryngol 2014;2014:569026

13 Dhiman NK, Vishwakarma AK, Verma V, Singh S. Non familial unilateral aplasia of submandibular gland. A rare finding. J Oral Maxillofac Radiol 2018;6:14-16

14 Thoeny HC. Imaging of salivary gland tumours. Cancer Imaging 2007;7(01):52-62

15 Scully C, Bagán JV, Eveson JW, Barnard N, Turner FM. Sialosis: 35 cases of persistent parotid swelling from two countries. Br J Oral Maxillofac Surg 2008;46(06):468-472 